\title{
Jurnal

\section{PREDIKSI KASUS PENYAKIT TUBERKULOSIS PARU DI KABUPATEN PONOROGO DILIHAT DARI STATUS NUTRISI}

\section{Prediction of Case Tuberculosis Disease in Ponorogo District Based on Nutritional Status}

\section{Sri Andayani}

Fakultas Ilmu Kesehatan Universitas Muhammadiyah Ponorogo, Indonesia

\section{Riwayat artikel}

Diajukan: 9 Agustus 2020

Diterima: 11 Februari 2021

\section{Penulis Korespondensi:}

- Sri Andayani

- Universitas

Muhammadiyah

Ponorogo

e-mail:

andayani_86@yahoo.com

\section{Kata Kunci:}

Prediksi, Status nutrisi, TB Paru

\begin{abstract}
Abstrak
Pendahuluan : Penilaian kemajuan dan keberhasilan penanggulangan penyakit Tuberkulosis paru dapat menggunakan indikator salah satunya yaitu angka penjaringan suspek dengan melakukan promosi kesehatan khususnya TB paru yang bekerja sama dengan PromKes Kabupaten Ponorogo.Tujuan: Menganalisa prediksi kasus penyakit Tuberkulosis Paru di Kabupaten Ponorogo dilihat dari status nutrisi. Metode: penelitian descriptif dengan pendekatan cross sectional. Populasi dan sampel menggunakan seluruh data status nutrisi pada kasus TB Paru BTA Positif di Kabupaten Ponorogo. Hasil: terjadi peningkatan distribusi kasus tuberculosis paru di kabupaten ponorogo tahun 2011 sampai 2015 yakni tahun 2011 sebanyak 276, tahun 2012 sebanyak 392, tahun 2013 sebanyak 378, tahun 2014 sebanyak 293 dan 334 kasus pada tahun 2015. Setelah diprediksikan, kejadian TB Paru dari tahun 2016 sampai dengan 2020 akan mengalami penurunan sejumlah 299 kasus ditahun 2016 dan 306 kasus ditahun 2020. Setelah dilakukan analisis time series didapatkan hasil bahwa prediksi kasus Tuberkulosis paru BTA positif di Kabupaten Ponorogo dilihat dari status nutrisi mengalami penurunan. Kesimpulan: Berdasrkan hasil analisis time series untuk mengetahui prediksi kejadian TB Paru dilihat dari status nutrisi yakni obesitas, nutrisi lebih, nutrisi normal dan nutrisi kurang menggunakan persamaan model trend quadratic.
\end{abstract}

\section{Abstract}

Background: Assessment of progress and success in overcoming pulmonary tuberculosis can use indicators, one of which is the number of suspects by conducting health promotion, especially pulmonary tuberculosis in collaboration with the Health Promotion of Ponorogo Regency. Objectives: To analyze the prediction of cases of tuberculosis in Ponorogo Regency in terms of nutritional status. Method: quantitative descriptive study using cross sectional design. Population and sample used all nutritional status data in cases of smear positive lung TB in Ponorogo Regency. Results: The distribution of smear positive lung TB cases in the period 2011 - 2015 tended to increase, namely in 2011 as many as 276, in 2012 as many as 392, in 2013 as many as 378, in 2014 as many as 293 and 334 cases in 2015. After prediction, the incidence of tuberculosis from 2016 to 2020 will experience a decrease of 299 cases in 2016 and 306 cases in 2020. Based on the results of the time series analysis with the trend method, the results show that the prediction of positive smear pulmonary tuberculosis cases in Ponorogo Regency, seen from the nutritional status, has decreased. Conclusio: the results of time series analysis with the trend method, to calculate the prediction of pulmonary tuberculosis cases in the nutritional status of the obesity group, over nutrition, normal nutrition and under nutrition using the quadratic trend model equation. 


\section{PENDAHULUAN}

Tuberkulosis paru merupakan penyakit yang disebabkan oleh mycobacterium tuberkulosis dan bersifat menular. Tuberkulosis disebabkan oleh mikroorganisme kompleks Mycobacterium tuberculosis. Kompleks ini mencakup Mycobacterium Tuberculosis, yaitu agen penyebab penyakit mikobakterial yang paling penting dan paling sering ditemukan pada manusia.

Penderita Tuberkulosis paru semaikin tahun semakin bertambah. Hal ini berdasrkan pada data hasil pemeriksaan Basil Tahan Asam yang positif di tahun 2011-2015. Di tahun 2011 dari 859.302 penduduk ditemukan kasus tuberkulosis sebesar 276 kasus, tahun 2012 dari 863.890 penduduk sejumlah 392 penderita, sejumlah 861.806 penduduk di tahun 2013 didapatkan 378 kasus, di tahun 2014 dari 865.809 penduduk didapatkan 293 kasus dan dari 867.393 penduduk ditemukan 334 penderita tuberkulosis paru BTA positif (Dinas Kesehatan Kabupaten Ponorogo, 2016).

Kasus tuberkulosis paru sematamata tidak hanya disebabkan oleh bakteri akan tetapi ada beberapa faktor lain yang sangat berpengaruh terhadap tuberkulosis paru. Faktor tersebut bisa dari diri pasien sendiri (usia, jenis kelamin, penyakit penyerta, status gizi/nutrisi, imunisasi, kebiasaan merokok) dan faktor eksternal (lingkungan, sosial ekonomi) (Atik, 2013).

Status gizi yang kurang pada orang dewasa mengakibatkan kelemahan fisik dan daya tubuh, sehingga meningkatkan kepekaan terhadap infeksi dan penyakit lainnya. Kekurangan gizi juga dapat berpengaruh terhadap kekuatan daya tahan tubuh dan respon imunologik terhadap penyakit dan meningkatkan resiko meningkatkan kejadian TB paru

Dari penjabaran diatas penulis termotivasi untuk melakukan penelitian tentang prediksi kasus penyakit Tuberkulosis Paru di Kabupaten Ponorogo dilihat dari status nutrisi.

\section{METODE}

Penelitian descriptive dengan menggunkan analisi time series. Populasinya adalah semua data sekunder yang diambil mulai bulan Januari 2011 sampai dengan bulan Desember tahun 2015 penderita Tuberkulosis paru yang tercatat di seluruh puskesmas di ponoro yang kemudian data tersebut dikirim ke dinas kesehatan kabupaten ponorogo pasien tuberkulosis paru dengan menggunakan teknik total sampling dan pengambilan data dilakukan bulan Oktober tahun 2016

\section{HASIL DAN PEMBAHASAN}

1. Hasil Prevalensi kasus Tuberkulosis Paru Berdasarkan Status Nutrisi di Kabupaten Ponorogo Tahun 2011-2015 Tabel 1.1 Hasil Prevalensi Kejadian TB Paru Berdasarkan Status Nutrisi di Kabupaten Ponorogo Tahun 2011-2015

\begin{tabular}{|c|c|c|c|c|c|}
\hline $\begin{array}{c}\text { Karaktrwiatik } \\
\text { usia }\end{array}$ & 2011 & 2012 & $\begin{array}{c}201 \\
3\end{array}$ & 2014 & 2015 \\
\hline a. Obesitas & 32 & 29 & 41 & 29 & 38 \\
\hline b. Lebih & 43 & 52 & 47 & 41 & 47 \\
\hline c. Normal & 87 & 78 & 113 & 68 & 108 \\
\hline d. Kurang & 114 & 233 & 177 & 155 & 141 \\
\hline Jumlah & 276 & 392 & 378 & 293 & 334 \\
\hline \multicolumn{6}{|c|}{ Sumber: Data Sekunder tahun 2016} \\
\hline data & alens & & asus & & nyakit \\
\hline
\end{tabular}

Tuberkulosis Paru di Kabupaten Ponorogo dilihat dari status nutrisi semua data didapatkan lebih dari 50\% setiap tahunnya, yakni 144 kasus $(41,3 \%)$ pada tahun 2011, 233 kasus $(59,4 \%)$ di tahun 2012, 177 kasus $(46,8 \%)$ di tahun 2013, 155 kasus $(52,9 \%)$ di tahun 2014 dan tahun 2015sebanyak 141 kasus $(42,2 \%)$

2. Hasil R Square pada Analisis Metode Trend

Tabel 1.2 Hasil R Square Terhadap Pemilihan Analisis Metode Trend Terhadap Prevalensi Kejadian TB Paru Berdasarkan Status Nutrisi di Kabupaten Ponorogo Tahun 2011-2015 


\begin{tabular}{|c|c|c|c|c|}
\hline \multirow{3}{*}{ Status Nutrisi } & \multicolumn{4}{|c|}{ R Scuare } \\
\hline & Linear & Quadr & Exponer & Pemili \\
\hline & & tic & ial & han \\
\hline a. Obesitas & 0,121 & 0,121 & 0,118 & Quadr \\
\hline b. Lebih & 0,001 & 0,075 & 0,000 & Quadr \\
\hline c. Normal & 0,069 & 0,084 & 0,047 & Quadr \\
\hline d. Kura & 0,007 & 0,485 & 0,000 & $\begin{array}{c}\text { Quadr } \\
\text { atic }\end{array}$ \\
\hline
\end{tabular}

Sumber: Data Sekunder tahun 2016-2020

Dari data diatas bahwa pemilihan analisis metode trend yang paling cocok untuk dipergunakan adalah model quadratic, karena pada model quadratic didapatkan prosetase $R$-Square yang terbesar

3. Hasil Prediksi Kasus Tuberkulosis Paru Tabel 1.3 Distribusi hasil Prediksi Kejadian TB Paru diKabupaten POnorogo Tahun 2016-2020 Berdasarkan Kelompok Status Nutrisi Tahun 2011-2015

\begin{tabular}{|c|c|c|c|c|}
\hline \multirow[t]{2}{*}{ Tahun } & & \multicolumn{3}{|c|}{$\begin{array}{c}\text { Hasil Prediksi kasus } \\
\text { tuberculosis paru } \\
\text { dikabupaten ponorogo tahun } \\
\text { 2016-2020 dilihat dari status } \\
\text { nutrisi } \\
\end{array}$} \\
\hline & Obesitas & Lebih & Normal & Kurang \\
\hline 2016 & 41 & 45 & 87 & 136 \\
\hline 2017 & 70 & 47 & 87 & 183 \\
\hline 2018 & 118 & 47 & 88 & 197 \\
\hline 2019 & 184 & 46 & 92 & 178 \\
\hline 2020 & 269 & 44 & 100 & 126 \\
\hline
\end{tabular}

Sumber : Data Sekunder tahun 2016-2020

Dari hasil analisis diatas prediksi prevalensi penyakit tuberculosis paru pada status nutrisi penderita obesitas, nutrisi lebih, nutrisi normal dan nutrisi kurang menggunakan persamaan model trend quadratic. Pada kelompok obesitas diprediksikan angka kasus TB Paru akan mengalami peningkatan disetiap tahunnya. Sedangkan pada kasus nutrisi kurang di awal dan pertengahan tahun akan meningkat, sedangkan di akhir tahun akan menurun. Hasil prediksi kejadian
Tuberkulosis Paru berdasarkan kelompok obesitas, didapatkan data 41 kasus ditahun 2016, 70 kasus ditahun 2017, 118 kasus ditahun 2018, 184 kasus ditahun 2019 dan 269 kasus tahun 2020. Pada kelompok nutrisi lebih akan meningkat di awal tahun dan menurun di akhir tahun, didapatkan hasil prediksi terdapat 45 kasus pada tahun 2016, 47 kasus ditahun 2017, ada 47 kasus ditahun 2018, ada 46 kasus ditahun 2019 dan tahun 2020 terdapat 44 kasus.

Kemudian pada status nutrisi normal tidak mengalami kenaikan yang signifikan disetiap tahunnya, didapatkan hasil prediksi 87 kasus ditahun 2016, 87 kasus di tahun 2017, 88 kasus di tahun 201892 kasus di tahun 2019 tahun 2020 sebesar 100 kasus. Sedangkan pada kelompok nutrisi kurang diprediksikan angka kasus TB Paru di awal dan ditengah tahun akan meningkat, dan diakhir tahun akan menurun. Hasil prediksi kejadian TB Paru bertdasarkan kelompok nutrisi kurang, 126 kasus (2016), 183 kasus (2017), 197 kasus (2018), 178 kasus (2019) dan 126 kasus (2020).

Kejadian Tuberkulosis Paru pada status nutrisi, yakni penderita yang terkena Tuberkulosis paru hampir seluruhnya tidak terjangkit HIV sebanyak 1536 penderita TB paru (91,8\%), sedangkan sebagian kecil penderita TB paru terjangkit HIV sebagai penyakit penyerta sebanyak 137 penderita TB paru $(8,2 \%)$. Hal tersebut karena adanya gizi yang kurrang menyebabkan pasien mengalami kelemahan dan beresiko tinggi terhadap infeksi/penyakit. Menurut Rukmini (2011), gizi yang kurang saling berkaitan dengan terjadinya infeksi. Seseorang yang mengalami kekurangan gizi sangat beresiko terjadi infeksi, kekebalan dadalam tubuh seseorang tidak mampu melawan kuman yang masuk ke dalam tubuh. respon imunologik terhadap penyakit dan meningkatkan resiko terjadinya tuberculosis paru.

Berdasarkan WHO (2014), efek negarif dari kekurangan nutrient yang menyebabkan malnurisi menyebabkan seseorang mengalami penurunan imun 
tubuh. Imun yang turun sehingga menyebabkan terjadinya penyakit tuberkolusis paru dengan hasil BTA Positif. Tidak ada systemic review yang menunjukkan bahwa ada hubungan yang kuat antara status gizi dengan risiko tuberkulosis, dan tidak ada dampak perubahan status gizi seseorang untuk menjadi TB di kemudian hari.

Hasil penelitian Masdewi (2016) menunjukkan bahwa sesorang yangmendrita penyakit tuberculosis paru denga satatus gisi yang baik apabila didapatkan IMT $>18,5 \mathrm{~kg} / \mathrm{m} 2$, sedangkan status gizi yang kurang apabila IMT $<18,5 \mathrm{~kg} / \mathrm{m} 2$. WHO mengungkapkan bahwa ada hubungan yang erat anatra status nutrisi dengan resiko keadaian penyakit tuberculosis paru, hal iani terjadi karena adanay kekurangan makro/mikronutrisi didalam tubuh sehingga mempengaruhi imunitas tubuh seseorang.

Dari prediksi kasus Penderita TB paru penelitian ini terbanyak terjadi pada penderita dengan status obesitas yang diprediksikan terjadi peningkatan disetiap tahun. Didukung penelitian Priyamtomo (2014) bahwa pada IMT overweight dan obesitas kemungkinan reinfeksi TB dapat terjadi apabila IMT yang berlebihan menyebakan penyakit metabolik yakni diabettus mellitus. Sedangkan hasil prediksi kejadian TB paru berdasarkan status nutrisi kurang mengalami peningkatan pada awal tahun, data prediksi kejadian tertinggi pada tahun 2018 yaitu 197 kasus. Pasien tuberculosis paru yang mengalami penurunan berat badan secara drastic merupakan salah satu tanda gejala seseorang mengalami penurunan imunitas tubuh dan merupaan prognosa dari penyakit tuberculosis paru tersebut (vasanta, 2008)

Hasil penelitian ini sejalan dengan penelitian yang dilakukan oleh Sarce dan Suniartianti tahun 2016 yang menunjukkan bahwa penderita TB paru terbanyak pada penderita dengan status gizi baik sebanyak 74 orang $(92,5 \%)$. Pada penelitian ini gizi baik bila IMT $>18,5 \mathrm{~kg} / \mathrm{m} 2$ dan gizi kurang bila IMT $<18,5 \mathrm{~kg} / \mathrm{m} 2$. Hal ini berbeda dengan keterangan WHO tahun 2014 yang menyatakan bahwa malnutrisi meningkatkan risiko terjadinya $\mathrm{TB}$, oleh karena efek negatif dari kekurangan makronutrien dan mikronutrien terhadap sistem imun. Tidak ada systemic review yang menunjukkan bahwa ada hubungan yang kuat antara status gizi dengan risiko tuberkulosis, dan tidak ada dampak perubahan status gizi seseorang untuk menjadi TB di kemudian hari. Peneliitian lain yang dliakukan oleh Sultan dkk di Bagdad menunjukkan bahwa BMI pada subjek TB lebih rendah $(16 \pm 1.1 \mathrm{~kg} / \mathrm{m} 2)$ dibandingkan dengan kelompok kontrol (23.5 $\pm 2.1 \mathrm{~kg} / \mathrm{m} 2$ ) dengan nilai $\mathrm{p}<0.05$ ( Sultan $\mathrm{K}$ et al.,2012

\section{KESIMPULAN}

Prediksi penyakit Tuberkulosis paru terus meningkat dari tahun 2016 sampai dengan 2020 dan mencapai titik tertinggi pada tahun 2020 yakni didapatkan 269 kasus pada penderita obesitas dengan penemuan kasus tertinggi, kasus nutrisi lebih dengan jumlah 44 kasus, kasus normal dengan jumlah 100 kasus dan pada status nutrisi kurang sebesar 121 kasus. Perlu dilakukan penelitian lebih lanjut dengan menyediakan berbagai macam bentuk atau model keakuratan hasil peramalan mengenai kejadian penyakit TB Paru, sehingga data hasil prediksi lebih akura.

\section{DAFTAR PUSTAKA}

Alimul,. Aziz. 2003. Riset Keperawatan dan teknik Penulisan ilmiah Jakarta : Salemba Medika

Atik, P. 2013. Faktor-faktor yang berhubungan dengan kejadian Tuberkulosis. paru pada .usia dewasa (study kasus dibalai pencegahan dan pengobatan penyakit.paru). (http://illeprints.undip.ac.id/5283)

Dinkes Jatim. 2014. Profil Kesehatan Propinsi Jawa timur. (www.dinkesjatimprov.co.id) 
Dinkes Kab. Ponorogo 2013. Profil Kesehatan Kabupaten Ponorogo Tahun 2012. Ponorogo : Dinkes kabupaten Ponorogo

Erika, Ani, dan Meidiana. 2016. Faktor yang Mempengaruhi Efikasi Diri pada Pasien TB Paru. Journal of Nursing and Health (JNH), Edisi 2, No 1, Hal 242-282. ISSN ; 25021524

Harry Iskandar, Heda Melinda D. Nataprawira, Herry Garna, Julistio T.B. Djais. Tuberculosis prevalence among underfive children in household contact with negative acid fast bacilli adult pulmonary tuberculosis. Vol. 48, No. 1, January 2008.

Hendy Tannady and Fan Andrew, Comparatyf analisys of linear regression metodh and exsponential smooting in error level parameter. Vol 02 No 07/July-September 2013.

Kementerian Kesehatan Republik Indonesia. 2012. Pedoman Nasional Penanggulangan Tuberkulosis. Jakarta : Direktrat Jendral Pengendalian Penyakit dan Penyehatan Lingkungan.

Mahfuzhah, I. (2014). Gambaran faktor risiko penderita TB paru berdasarkan status gizi dan pendidikan di RSUD Dokter Soedarso. Jurnal Mahasiswa PSPD FK Universitas Tanjungpura, $1(1), 1-13$.

Priyamtomo, E.P, dr. Abdul Salam Sp.P2 , Agustina Arundina S.Gz, M.Ph3 2014. Description of Body Mass Index in Tuberculosis Patient with Anti Tuberculosis Drugs Therapy in Unit Pengobatan Penyakit Paru Paru (UP4) Pontianak

Scare and Suarni. 2016. Faktor yang
Berhubungan dengan Kejadian Tb Paru Di Rsud Labuang Baji Makassar. Jurnal Ilmiah Kesehatan Diagnosis Volume 9 Nomor 2 Tahun 2016. ISSN : 2302-172.

Trans Tuberkulosis. 2011. Strategi nasional pengendalian tuberkulosis tahun 2010-2014 : Terobosan mепији sukses universal. Jakarta : direktoral jenderal pengendalian penyakit dan penyehatan lingkungan

Sugiyono. 2013. Statistika Untuk Penelitian. Bandung : Alfabeta

Sultan, R; Et al., 2012, Moderate to Severe Malnutrition in Patients with Tuberculosis is A Risk Factor Associated with Early Death, Transaction of The Royal Society Of Tropical Medicine and Hygiene, 15 96: 291-294. Available from

Umardani, K. 2010. Community knewladge, attitude and behaviour related to tuberculosis (TB) paru in sungai tarab subdistriction.

Vasantha, Seyed Muhammad; Salami Nejad., 2008, The Cause and Risk Factors of Tuberculosis Death in Khuzestan, Acta Medica Iranica, 47(2): 89-92

WHO. 2003. Global Tuberculosis ControlEpidemiology, Strategy, Financing. Geneva: World Health Organisation.

World. Health Organization. 2014. Global Tuberkulosis Control. Report 2014. (online)

(Http://apps.who.int/iris/bitstream/pu blications/globalreport/10065/13709 4/1/9789241564809_eng.pdf?ua=1)

World. Health Organization. 2014. Global Tuberkulosis Control. Report 2014. (online)

(Http://apps.who.int/iris/bitstream/pu blications/globalreport/10065/13709 4/1/9789241564809_eng.pdf?ua= 